\title{
Forecasting High-Impact Weather in Landfalling Tropical Cyclones Using a Warn-on-Forecast System
}

\author{
Thomas Jones, Patrick Skinner, Nusrat Yussouf, Kent Knopfmeier, \\ Anthony ReINHART, AND DaVID DoWell
}

\begin{abstract}
WoF SYSTEM AND TC OVERVIEWS. Initial Warn-on-Forecast (WoF) systems have been designed for the prediction of convection driven by overland synoptic and mesoscale forcing; however, the overall concept is also applicable to landfalling tropical cyclones (TCs). The WoF system known as the National Severe Storms Laboratory (NSSL) Experimental Warn-on-Forecast System for Ensembles (NEWS-e) was tested retrospectively during the landfalling phases of Hurricanes Irma and Harvey and used to generate short-term $(0-3 \mathrm{~h})$, probabilistic forecasts of precipitation, supercell rotation (e.g., mesocylones), and wind speed. The WoF system generates analyses at 15-min intervals through rapidly cycled assimilation of Weather Surveillance Radar-1988 Doppler (WSR-88D) reflectivity and radial velocity observations and Geostationary Operational Environmental Satellite-16 (GOES16) satellite cloud water path observations, using an
\end{abstract}

AFFILIATIONS: JONES, KNOPFMEIER, AND REINHART-Cooperative Institute for Mesoscale Meteorological Studies, University of Oklahoma, and NOAA/National Severe Storms Laboratory, Norman, Oklahoma; SKINNER AND YUssouf-Cooperative Institute for Mesoscale Meteorological Studies, and School of Meteorology, University of Oklahoma, and NOAA/National Severe Storms Laboratory, Norman, Oklahoma; DoweLL—NOAA/OAR/Earth System Research Laboratory, Boulder, Colorado

CORRESPONDING AUTHOR: Dr. Thomas A. Jones,

thomas.jones@noaa.gov

The abstract for this article can be found in this issue, following the table of contents.

DOI:10.II75/BAMS-D-18-0203.I

(C)2019 American Meteorological Society

For information regarding reuse of this content and general

copyright information, consult the AMS Copyright Policy. ensemble Kalman filter (EnKF) technique (Wheatley et al. 2015; Jones et al. 2016). Following assimilation, ensemble forecasts are launched multiple times per hour and provide accurate, up-to-date probabilistic guidance for hazards within individual convective storms (Skinner et al. 2018). For both Harvey and Irma, the WoF system was initialized at 1800 UTC the day of landfall using initial conditions from the experimental High Resolution Rapid Refresh Ensemble (HRRRE; Benjamin et al. 2016; Alexander et al. 2018).

Harvey reached tropical storm status moving northward in the Bay of Campeche by 1800 UTC 23 August and hurricane status by 1800 UTC 24 August, then continued to rapidly intensify through 0000 UTC 26 August, when it reached category 4 status with maximum sustained winds of $115 \mathrm{kt}\left(1 \mathrm{kt} \approx 0.5144 \mathrm{~m} \mathrm{~s}^{-1}\right)$. Harvey made landfall shortly afterward at 0300 UTC near Rockport, Texas (Blake and Zelinsky 2018). Immediately preceding and during landfall, a well-formed rainband was moving on shore in southeastern Texas. Present within this rainband were rotating mini supercells (Eastin and Link 2009) that generated several tornadoes between 1900 and 0300 UTC (Table 1). After landfall Harvey slowed considerably, leading to largescale flooding in southeastern Texas.

Around the time Harvey made landfall in Texas, a tropical wave was emerging off Africa into the Atlantic that developed into tropical storm Irma by 0600 UTC 30 August (Cangialosi et al. 2018). Irma quickly intensified and reached hurricane status by 0600 UTC 31 August. Irma continued to intensify, becoming a category 5 hurricane with maximum sustained winds of $155 \mathrm{kt}$ on 1800 UTC 5 September. Irma moved west-northwest through the Atlantic before making landfall in Cuba as a major hurricane. A weakened Irma turned northward toward Florida on 9 September and made landfall near Marco Island 


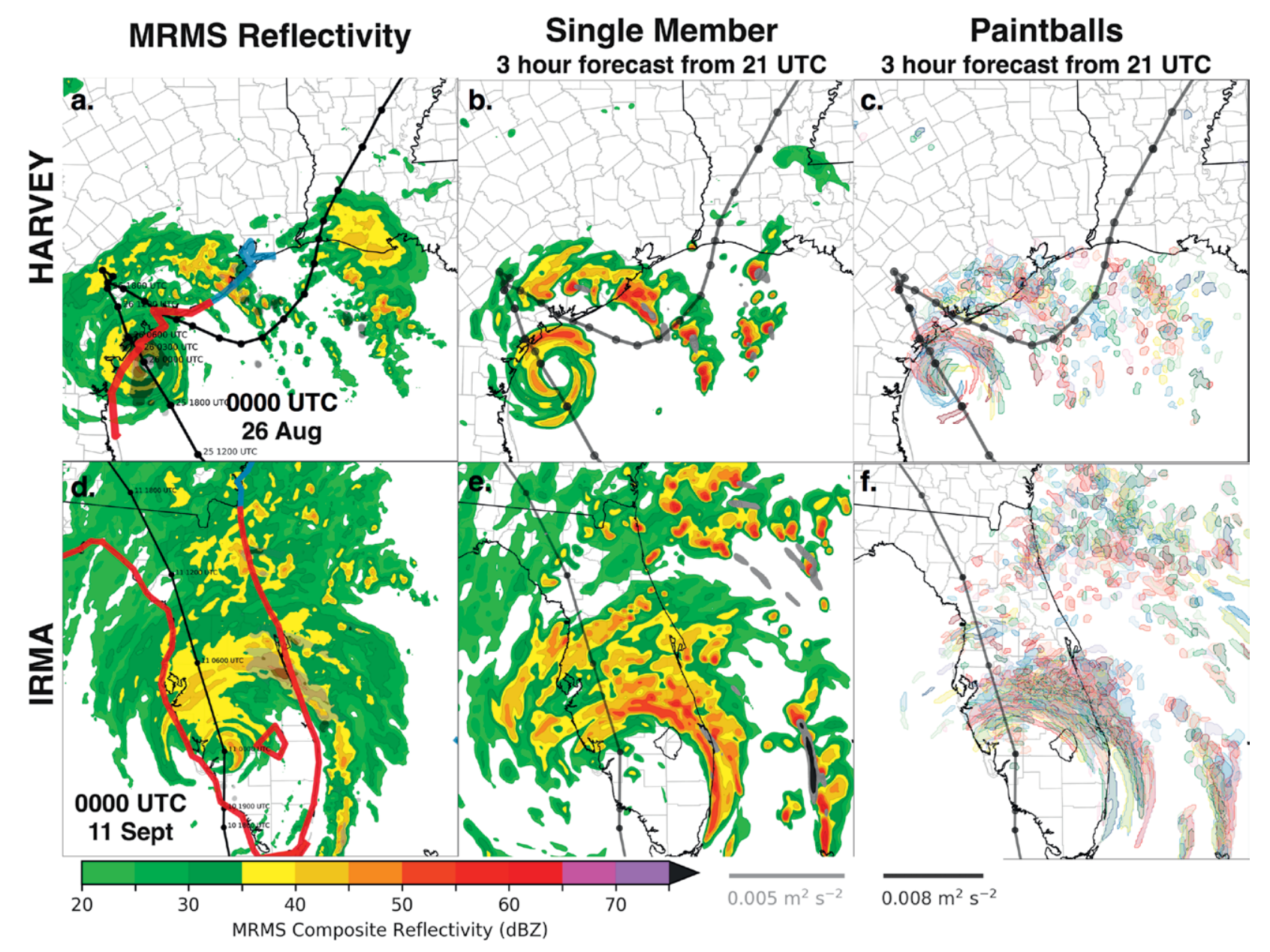

FIG. I. (a),(d) MRMS composite reflectivity (dBZ) at 0000 UTC 26 Aug 2017 and 0000 UTC II Sep 20 I7 showing Hurricanes Harvey and Irma, respectively. (b),(e) Corresponding simulated 3-h forecast reflectivity at 0000 UTC from a single ensemble member. (c),(f) Paintball plots showing areas of forecasts reflectivity greater than $40 \mathrm{dBZ}$ for all ensemble members at this time. Red (blue) lines along the coasts indicate the locations of valid hurricane (tropical storm) warnings at this time.

at 1930 UTC 10 September, while continuing on a northward trajectory. Like Harvey, Irma was associated with rainbands moving onshore that contained several mini supercells, which produced at least three tornadoes between 2200 and 0100 UTC 10-11 September along the eastern coast of Florida (Table 1).

FORECAST TC AND ENVIRONMENTAL CHARACTERISTICS. WoF system forecasts for both hurricanes generally produced accurate shortterm guidance of the tropical cyclone track, structure, and evolution of small-scale convective elements within their rainbands. Multi-Radar Multi-Sensor (MRMS) gridded composite reflectivity (Lakshmanan et al. 2007; Smith et al. 2016) for Harvey and Irma at 0000 UTC 26 August and 11 September, respectively, is provided in Fig. 1. The eye and eyewall of Harvey are clearly evident in Fig. 1a, as is the strong rainband to the northeast of the center of circulation. In the case of Irma (Fig. 1b), the reflectivity structure was much less symmetrical with no continuous eyewall present. ${ }^{1}$ However, the overall circulation is significantly larger

\footnotetext{
${ }^{1}$ The Key West, FL (KBYX), radar went down around 1600 UTC on 10 September. This likely resulted in some undetected precipitation on the south side of the system at 0000 UTC 11 September. However, information from other radars strongly supports the nonsymmetrical structure of Irma described.
} 
TABLE I. Tornado reports between 1900-0300 UTC for Harvey (25-26 Aug) and Irma (10-II Sep). Times and locations were gathered from the local storm report database and adjusted to remove duplicate information. Also, the number of tornado reports is likely underestimated compared to the true count based on research by Martinaitis (2017).

\begin{tabular}{|c|c|c|c|c|}
\hline \multicolumn{5}{|c|}{ Harvey } \\
\hline Day & Time (UTC) & Lon $\left({ }^{\circ}\right.$ E) & Lat $\left({ }^{\circ} \mathbf{N}\right)$ & EF scale \\
\hline 25 & 1923 & -94.77 & 29.31 & 0 \\
\hline 25 & 2022 & -95.49 & 28.97 & 0 \\
\hline 25 & 2030 & -95.91 & 28.74 & 0 \\
\hline 25 & 2030 & -95.56 & 29.03 & 0 \\
\hline 25 & 2045 & -95.96 & 28.83 & 0 \\
\hline 25 & 2047 & -94.77 & 29.31 & 0 \\
\hline 25 & 2114 & -96.67 & 28.43 & I \\
\hline 25 & 2309 & -95.50 & 29.14 & 0 \\
\hline 26 & 0125 & -95.55 & 29.15 & 0 \\
\hline 26 & 0244 & -95.35 & 29.22 & 0 \\
\hline 26 & 0247 & -95.39 & 29.24 & 0 \\
\hline \multicolumn{5}{|c|}{ Irma } \\
\hline 10 & 2227 & -81.67 & 28.93 & I \\
\hline 10 & 2350 & -81.31 & 29.96 & I \\
\hline 11 & 0020 & -81.21 & 29.65 & 0 \\
\hline
\end{tabular}

than Harvey and several rainbands are apparent north of the center. The 3-h reflectivity forecast initiated at 2100 UTC from a single ensemble member clearly shows the location of the eye in Harvey (Fig. 1b), while a similar forecast for Irma shows limited convection south and west of the eye (Fig. 1e). Paintball plots indicate the locations of composite reflectivity greater than $45 \mathrm{dBZ}$ from each ensemble member (Figs. 1c,f). For both hurricanes, most members in 3-h forecasts generally match observed reflectivity structures, as indicated by dense, overlapping fields of paintball objects. Despite general forecast similarities across the ensemble, significant spread in the model solutions for specific features was present. For example, the placement of western eyewall convection differs up to $30 \mathrm{~km}$ from the westernmost to the easternmost member in Hurricane Harvey (Fig. 1c).
The WoF system additionally provides information on the local storm environment useful for identifying regions with the greatest potential for tornado development (Fig. 2). The ensemble mean, mixed-layer convective available potential energy (CAPE) was maximized on the northeastern sides of the center of circulation, corresponding to the rainband locations in both hurricanes. In Harvey, a narrow axis of CAPE greater than $1,500 \mathrm{~J} \mathrm{~kg}^{-1}$ was moving onshore, while CAPE greater than $1,000 \mathrm{~J} \mathrm{~kg}^{-1}$ is present along much of the eastern Florida coast in Irma (Figs. 2a,d). Collocated with the moderate potential instability were areas of extreme $0-1-\mathrm{km}$ storm relative helicity (SRH) greater than $300 \mathrm{~m}^{2} \mathrm{~s}^{-2}$ (Figs. 2b,f) A sharp increase in $0-1-\mathrm{km}$ SRH was present along coastlines experiencing onshore flow owing to frictional effects and coincides with onshore penetration of moderate CAPE, producing a narrow corridor with the greatest potential for tornado development (Knupp et al. 2006; Green et al. 2011). The significant tornado parameter (STP) was developed to combine both instability and wind shear characteristics into a single parameter designed to emphasize areas where the probability of tornado occurrence was most likely (Thompson et al. 2012). In Harvey, STP exceeds 3 in the area maximum CAPE, but is much less near the eye where SRH is greater (Fig. 2c). The STP analysis for Irma was somewhat more complex at this time. There are several pockets of STP $>4$ along the eastern coast of central Florida, which would normally indicate a potential for strong (EF2+) tornadoes (Fig. 2f). Farther north, values of $\sim 1$ were present along the coast. However, low-level rotation and tornadoes were observed in both areas with similar frequency. The challenge for the WoF system is to determine if it can accurately predict individual areas of rotation within these broader regions of favorable environmental conditions.

\section{TC RAINBAND AND LOW-LEVEL ROTA-} TION FORECASTS. To assess the potential of forecasting low-level rotation within TC spawned convection, the forecast probability of $0-2-\mathrm{km}$ vertical vorticity greater than $0.0015 \mathrm{~s}^{-1}$ was generated approximately 120,60 , and $30 \mathrm{~min}(2,1$, and $0.5 \mathrm{~h}$ ) prior to a specific tornado report in each hurricane (Table 1). Note that model low-level vorticity forecasts only indicate the locations of mesocyclones that may produce tornadoes, as the current WoF system configuration cannot resolve individual tornadoes. However, it is still useful to compare low-level vorticity forecasts with tornado reports to assess the 


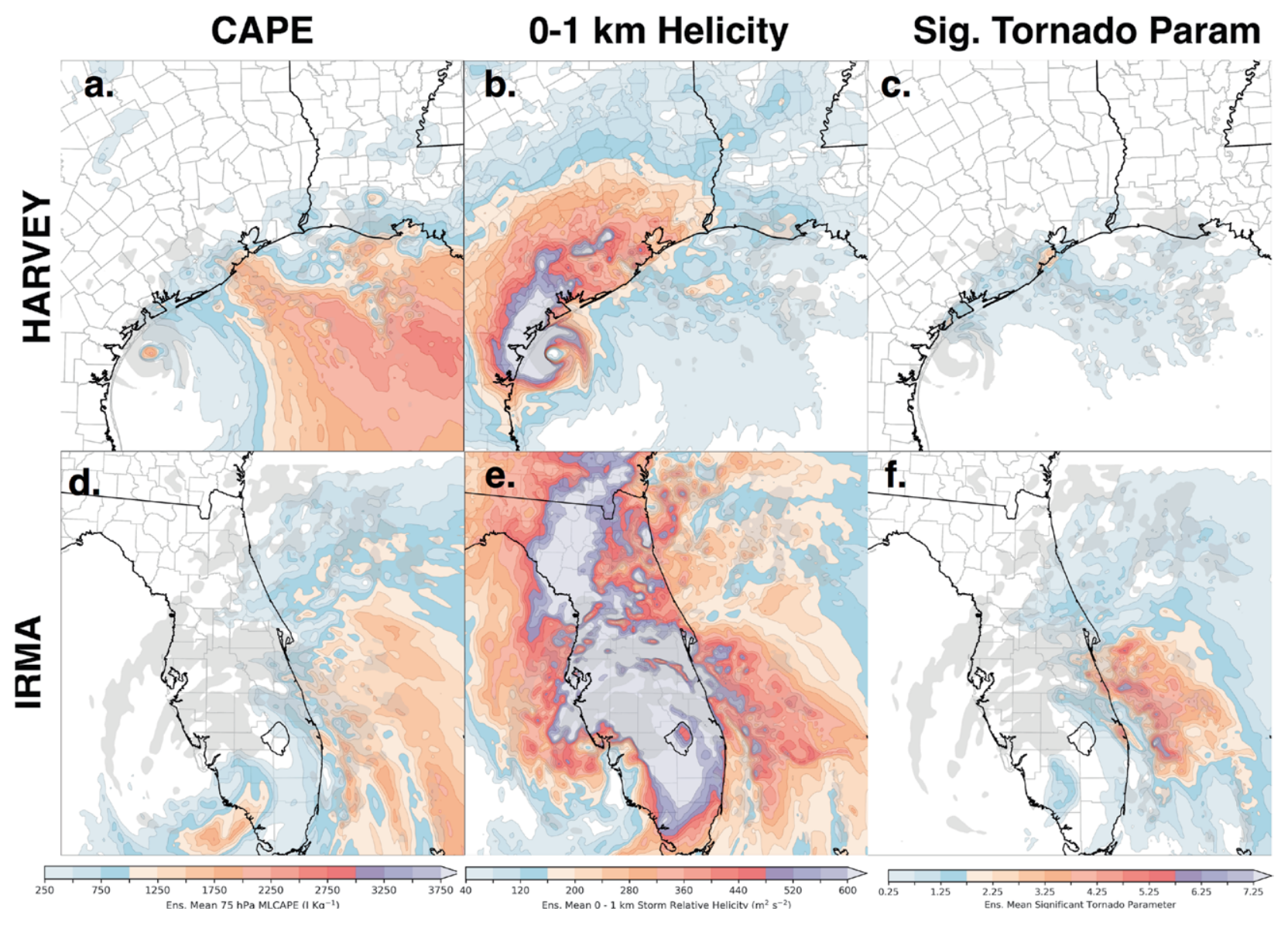

FIG. 2. Model ensemble mean analyses of (a),(d) 75-hPa mixed-layer CAPE (J kg-1); (b),(e) 0-I-km storm relative helicity $\left(\mathrm{m}^{2} \mathrm{~s}^{-2}\right)$; and (c),(f) STP for Harvey and Irma at 0000 UTC 26 Aug and II Sep 20I7, respectively. Gray shading indicates the location of probability matched mean reflectivity greater that $35 \mathrm{dBZ}$ at this time.

usefulness of the system in predicting mesocyclones and providing useful tornado warning guidance. For Harvey, one of several tornadoes was reported at 0125 UTC 26 August east of West Columbia (near the Texas coast) damaging trees, roofs, and outbuildings and was listed as a "high end" EF0. For 120-min forecasts initiated at 2330 UTC and ending at 0130 UTC, a broad swath of low-level vorticity probability exceeding $40 \%$ denotes the area where rotating supercells are likely to occur. The vorticity swath was rather broad and does not indicate the threat from a single storm at this time (Fig. 3a). However, this changes for forecasts initiated at 0030 UTC. For this period, a narrow vorticity swath with probabilities greater than $60 \%$ were forecast for the 60 -min period between 0030 and 0130 UTC (Fig. 3b). Finally, the 30-min forecast generates a small area of high vorticity probabilities, but they do not persist as this particular storm rapidly weakens after 0130 UTC (Fig. 3c). The tornado report is near the predicted vorticity swaths with 60 and $30 \mathrm{~min}$ of lead time, though there is some displacement of the forecast swaths to the northwest of the tornado report. Additionally, while a tornado warning was issued with this storm, it did not overlap with the tornado report or the areas of highest forecast low-level vorticity. While the vorticity swath and tornado report were not a perfect match, the forecast clearly depicted the area of highest tornado threat on spatial scales similar to a National Weather Service (NWS) tornado warning, as well as the brevity of the tornado threat as the storm moved inland. Additional EF0 tornadoes occurred in the same area after 0230 UTC and corresponding vorticity swaths were predicted at least an hour in advance of these tornadoes as well (not shown).

Rotation forecasts for Irma were successful in emphasizing localized areas where low-level rotation was likely, indicating increased potential for tornadoes to 


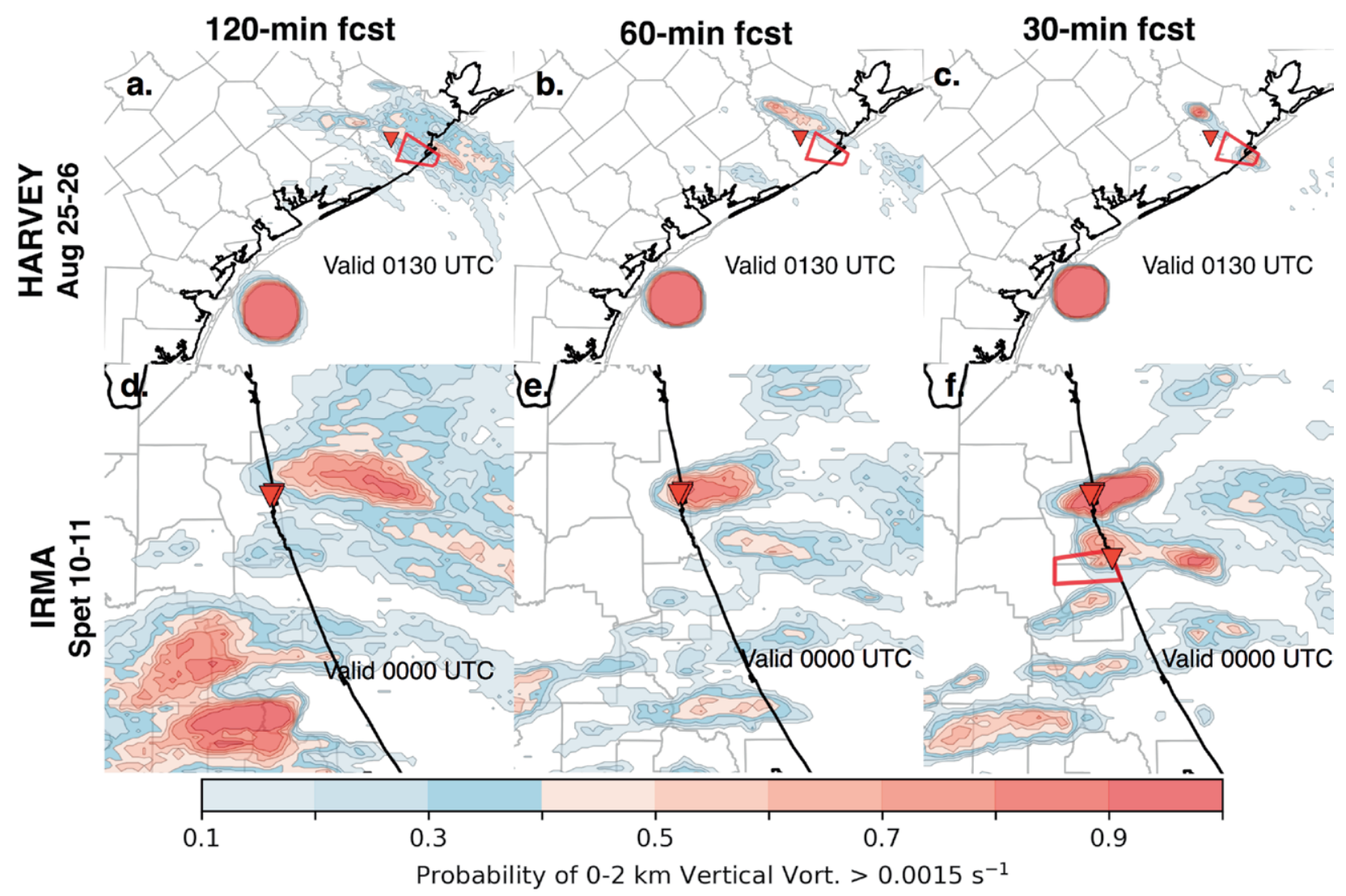

FIG. 3. Model forecast swaths of $0-2-\mathrm{km}$ vertical vorticity $\left(\mathrm{s}^{-1}\right)$ neighborhood (9-km radius) probability of exceeding $0.0015 \mathrm{~s}^{-1}$ for 120-, 60-, and 30-min forecasts ending at (a)-(c) 0130 UTC 26 Aug for Hurricane Harvey and (d)-(f) 0000 UTC II Sep for Hurricane Irma. Tornado reports (inverted red triangles) and tornado warnings (red polygons) valid during the forecast period are shown.

occur. Tornadoes were reported at 2350 and 0020 UTC near Villano Beach and Marineland along the northeastern coast of Florida (Table 1). These tornadoes were spawned by mini supercells located within the northernmost rainband. Two-hour forecasts of $0-2-\mathrm{km}$ vertical vorticity between 2200 and 0000 UTC highlight an area of enhanced tornado potential originating over the ocean and moving westward across the coastline at 0000 UTC, near the location of the Villano Beach tornado (Fig. 3d). The swath becomes more defined for forecasts initiated at 2300 and 2330 UTC (Figs. 3e,f). An additional but smaller vorticity swath was predicted farther south starting with the 2300 UTC forecast and corresponds to the Marineland tornado report at 0020 UTC. A tornado warning for the latter was issued at approximately 0010 UTC, providing a 10-min lead time, but no warning was issued for the Villano Beach tornado. Tornado warning lead time is typically lower for tornadoes occurring within landfalling tropical cyclones (Martinaitis 2017), and the results from Hurricanes Harvey and Irma suggest that a WoF system has the potential to improve warning lead time for tropical cyclone tornadoes.

While the two tornadic examples described above show promise, there remains many challenges to using the WoF system in tornado prediction during landfalling TCs. It is important to emphasize that the WoF system is used to predict low-level rotation within convection, which indicates the potential location for tornado development. However, the presence of low-level rotation alone does not indicate a tornado will occur. Factors corresponding to the overall storm structure and surrounding environment are also important. This is true for both tropical and continental convection. Forecast low-level rotation from the WoF system has been verified against observed MRMS low-level radar rotation objects, as described by Skinner et al. $(2016,2018)$. A similar verification technique was applied to Harvey and Irma low-level vorticity forecasts to determine if forecast skill is similar to that previously observed for continental convection. 


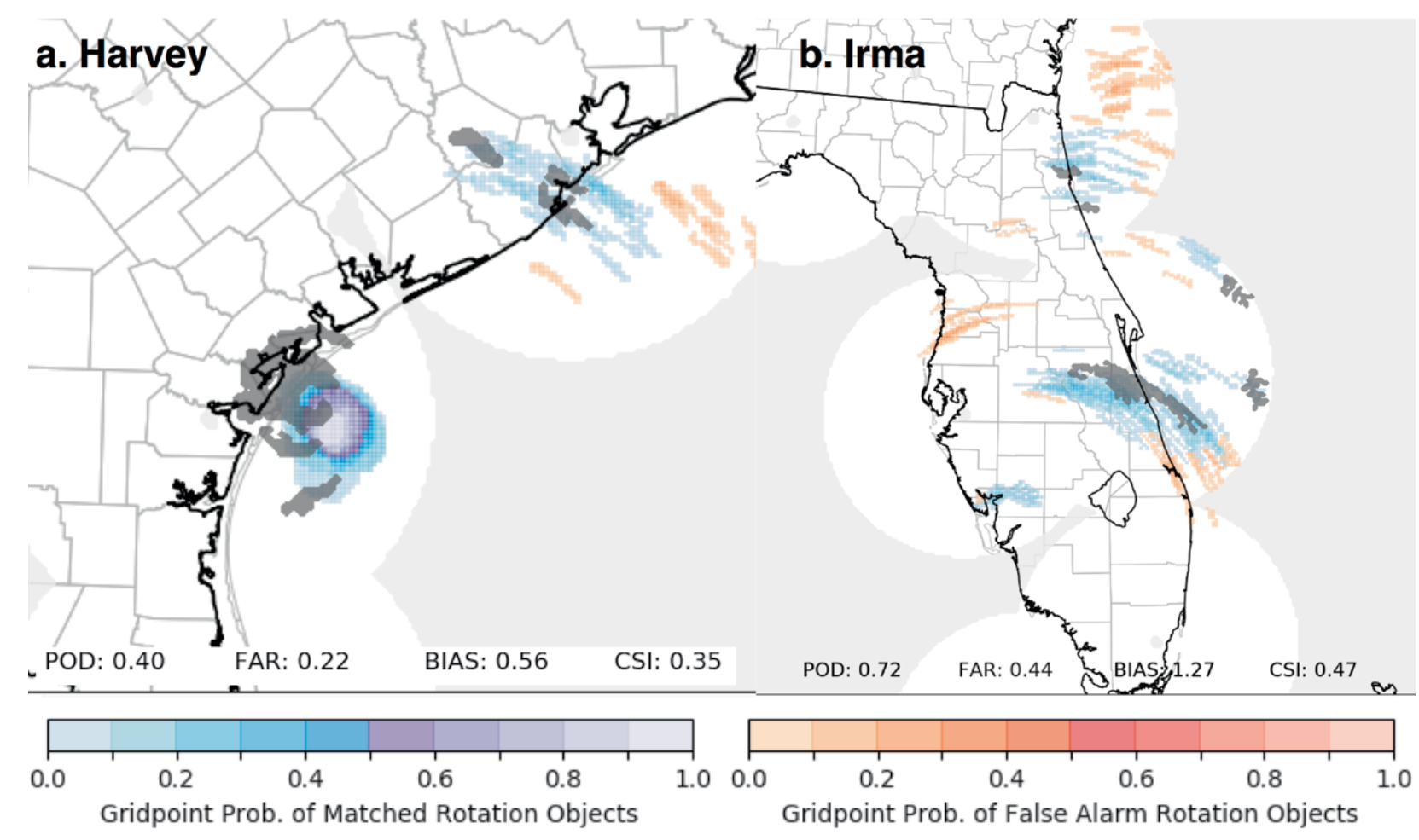

FIG. 4. Matched MRMS rotation and WoF system 0-2-km low-level vorticity objects for 2-h forecasts ending at (a) 0130 UTC 26 Aug and (b) 0000 UTC II Sep for Hurricanes Harvey and Irma, respectively. Gray shading indicates the location of MRMS rotation objects, blue indicates the location of matched forecast objects, and oranges indicate the location of false alarm objects.

Figure 4 shows 2 -h forecast low-level vorticity objects compared with radar-derived low-level rotation objects valid at the end of the forecast period at 0130 UTC 26 August and 0000 UTC 11 September for Hurricanes Harvey and Irma, respectively. In both cases, probability of detection was high, indicating the system is accurately predicting locations that are impacted by supercells. However, not all of the predicted regions of rotation correspond to supercells. In Harvey, most of the observed and rotation

TABLE 2. Object-based skill scores for ensemble mean 2-h forecasts of $\mathbf{0 - 2 - k m ~ v e r t i c a l ~ v o r t i c i t y ~ c o m p a r e d ~}$ with MRMS 0-2-km rotation objects averaged over forecasts initiated at hourly intervals from 1900 to 0300 UTC for both Hurricanes Harvey and Irma. POD = probability of detection, $F A R=$ false alarm ratio, $C S I=$ critical success index, and $B I A S=$ model bias.

\begin{tabular}{|l|c|c|c|c|}
\hline Hurricane & POD & FAR & BIAS & CSI \\
\hline Harvey & 0.64 & 0.70 & 1.2 & 0.45 \\
\hline Irma & 0.55 & $0.4 I$ & 1.5 & 0.25 \\
\hline
\end{tabular}

objects were associated with the eyewall, while in Irma a large area of rotation is evident in central Florida that was not associated with any reported tornadoes during this time. However, the areas of individual storm rotation are also evident in both hurricanes. In the case of Irma, the system appears to overforecast rotation, as evidenced by greater false alarm values for this forecast. Object-based skill scores were computed for all 2-h forecasts initiated at hourly intervals from 1900 to 0300 UTC to assess over system skill for each hurricane (Table 2). Overall, skill scores were comparable to those found during the verification of springtime testing (Skinner et al. 2018).

For both hurricanes, the WoF system was generally able to accurately forecast the areas with highest tornado threat within the larger overall circulation. These forecasts were made possible by a combination of realistic predictions of the storm environment, including locally favorable regions for tornado development, and analyses of individual storm cells through rapidly cycled assimilation of radar and satellite data. 
TC WIND FORECASTS. Beyond forecasting low-level rotation, the WoF system was also able to accurately predict the regions and intensity of the strongest winds within the hurricanes. For Hurricane Harvey, the probability of sustained $10-\mathrm{m}$ wind speed greater than $64 \mathrm{kt}$ (category 1 threshold) and the probability of $10-\mathrm{m}$ wind speed gusts greater than $96 \mathrm{kt}$ were calculated for a 3-h forecast initiated at 0000 UTC 26 August (Fig. 5). ${ }^{2}$ The probability of category 1 sustained winds from the WoF system was nearly $100 \%$ within a circular region around the eye. Probabilities remain high over the coastal areas, before decreasing rapidly inland.

High probabilities of wind gusts greater than $96 \mathrm{kt}$ were predicted over a smaller area that still included inland regions near the coastline. Corresponding paintball plots at 0300 UTC show the member-bymember distribution of the eye location and surrounding maximum winds (Figs. 5c,d). Overall, there is good agreement, except for one member (yellow) that was well southwest of the others. Finally, the 3-h 90th percentile sustained wind speeds and gusts provide a measure of the reasonable maximum wind speed predicted by the ensemble and indicate the potential for a major hurricane, forecasting values in excess of 100 and $120 \mathrm{kt}$, respectively (Figs. 5e,f). To determine the accuracy of these forecasts, they were compared against surface wind reports during this period (Table 3, Fig. 6). At five of the six sites along the Texas coast, maximum sustained wind speeds exceeded $70 \mathrm{kt}$, with a maximum speed of $96 \mathrm{kt}$ recorded at Sentinal at 0142 UTC. (Note that this report is from a $14-\mathrm{m}$ tower.) Corresponding 90th percentile values from forecasts initiated at 0100 UTC indicate similar, if somewhat higher, wind

${ }^{2}$ Surface winds speeds are diagnosed from the surface parameterizations found in the model to convert wind speed information on model levels to a $10-\mathrm{m}$ value. Various assumptions exist in these calculations that may affect the representativeness of model values to observations.
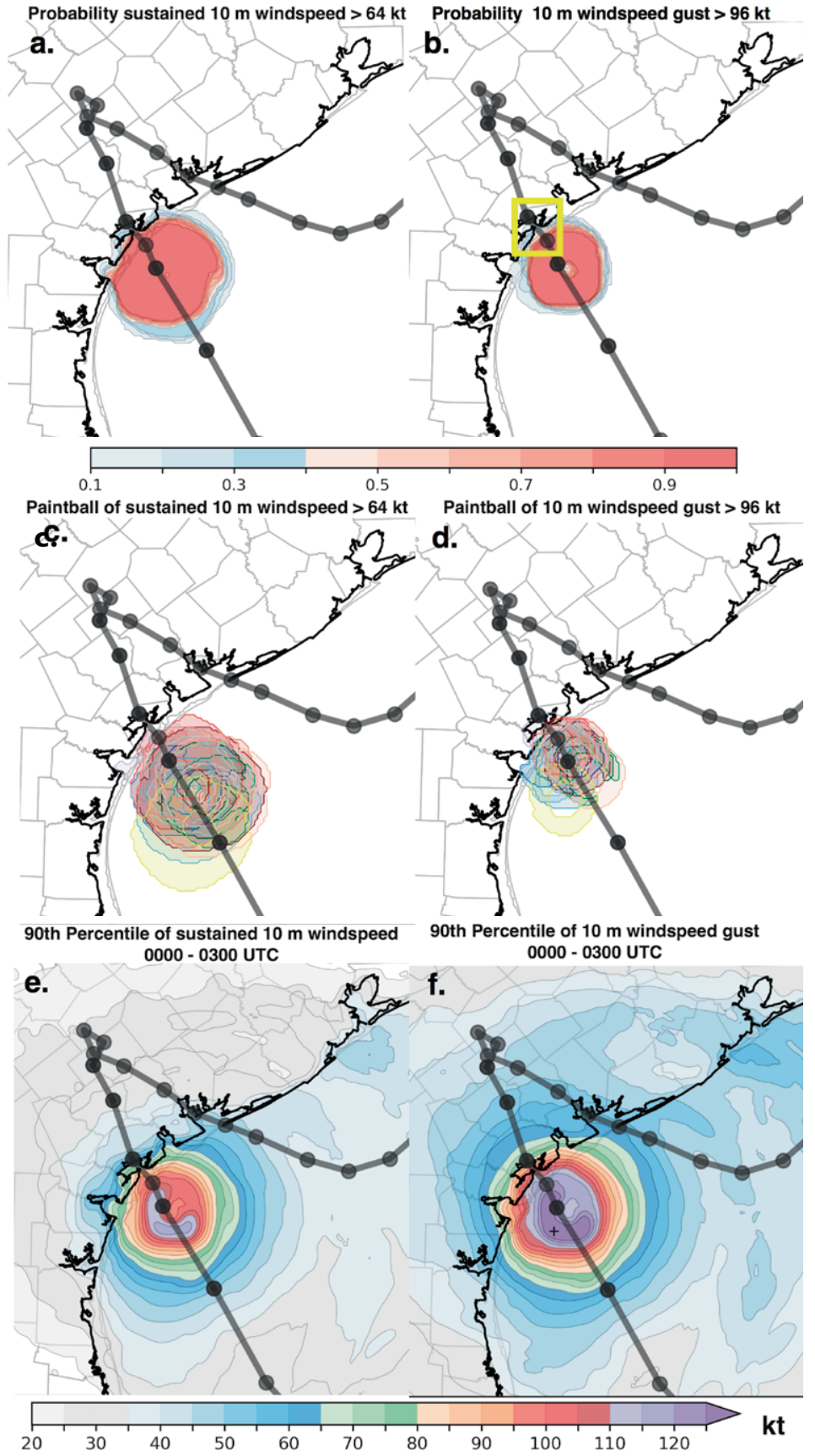

FIG. 5. (a),(b) Accumulated probability of $10-\mathrm{m}$ sustained wind speed greater than $64 \mathrm{kt}$ (category I threshold) and $10-\mathrm{m}$ gusts greater than $96 \mathrm{kt}$ for a 3-h forecast beginning at 0000 UTC 26 Aug. (c),(d) Paintball plots of sustained wind greater than 64 kt and gusts greater than $96 \mathrm{kt}$ valid at the end of the forecast period at 0300 UTC. Each color represents a different ensemble member. (e),(f) Ensemble 90th percentile sustained winds and gusts during the 3-h forecast period. National Hurricane Center (NHC) best track is overlaid on all panels for reference. Yellow box denotes area where ground-based wind observations are compared with model forecasts. See Fig. 6. 


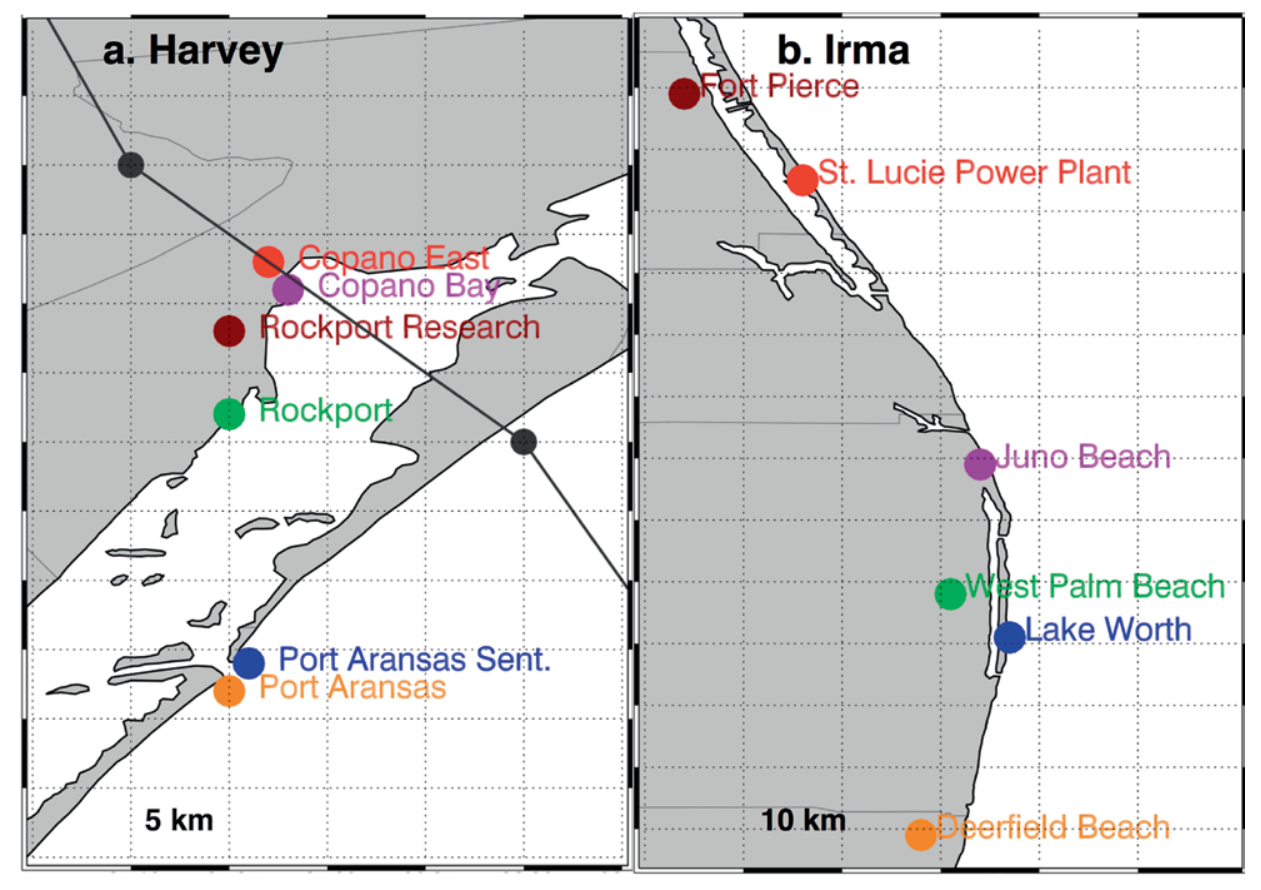

FIG. 6. Locations of selected wind observations where the strongest winds were observed during and after landfall of hurricanes Harvey and Irma (Tables 3, 4).

TABLE 3. Locations and times of the highest reported sustained wind speeds (kt) and gust during the landfalling period of Harvey between 0000 and 0400 UTC 26 Aug. Also listed are the 90th percentile forecasts' sustained wind speed and gust at these locations during the forecast period starting at 0000 UTC. Finally, the probability of forecast sustained winds $>64 \mathrm{kt}$ and gusts $>96 \mathrm{kt}$ is shown. Note that the Rockport sensor failed soon after the wind observation above was made. Site types are as follows: TCON = Texas Coastal Observing Network, NOS = National Ocean Service, C-MAN = Coastal-Marine Automated Network, NERRS = National Estuarine Research Reserve System, FL-Research = Florida Research Tower.

\begin{tabular}{|l|c|c|c|c|c|}
\hline Name & Lon $\left({ }^{\circ} \mathbf{E}\right)$ & Lat $\left({ }^{\circ} \mathbf{N}\right)$ & Time (UTC) & Site & Measurement \\
\hline Port Aransas Sentinel & -97.04 & 27.84 & 0142 & TCON & I min; $14 \mathrm{~m}$ \\
\hline Rockport & -97.05 & 28.02 & 0154 & NOS & $2 \mathrm{~min} ; 7.5 \mathrm{~m}$ \\
\hline Port Aransas & -97.05 & 27.82 & 0220 & C-MAN & $2 \mathrm{~min} ; 15 \mathrm{~m}$ \\
\hline Copano East & -97.03 & 28.13 & 0220 & NERRS & $2 \mathrm{~min} ; 7.5 \mathrm{~m}$ \\
\hline Rockport Research & -97.05 & 28.08 & 0252 & FL-Research & $1 \mathrm{~min} ; 10 \mathrm{~m}$ \\
\hline Copano Bay & -97.02 & 28.11 & 0306 & TCON & $2 \mathrm{~min} ; 10 \mathrm{~m}$ \\
\hline
\end{tabular}

\begin{tabular}{|l|c|c|c|c|c|c|}
\hline Name & Obs: Sustained & 90th \% & Obs: Gust & 90th \% & Prob > 64 kt & Prob > 96 kt \\
\hline Port Aransas Sentinel & 96 & 101.6 & 115 & 123.8 & I & I \\
\hline Rockport & 59 & 97.1 & 94 & 117.7 & 0.82 & 0.95 \\
\hline Port Aransas & 83 & 100.2 & 108 & 120.0 & 1 & 0.99 \\
\hline Copano East & 73 & 87.2 & - & 110.7 & 0.9 & 0.33 \\
\hline Rockport Research & 88 & 92.5 & 122 & 112.7 & 1 & 0.6 \\
\hline Copano Bay & 79 & 89.3 & 103 & 111.8 & 0.99 & 0.56 \\
\hline
\end{tabular}


speeds and were within $15 \mathrm{kt}$ of the observed value for all but one site. The probability of sustained category 1 winds exceeds $90 \%$ at all these sites, which was verified by the observations. The remaining site (Rockport) only recorded a sustained wind speed of $59 \mathrm{kt}$, but a gust of $94 \mathrm{kt}$, and had the lowest forecast probability of sustained category 1 wind speeds of any available site. However, this sensor failed soon after this observation was made. The WoF system also reasonably forecast wind speed gusts with observed values ranging from 94 to $122 \mathrm{kt}$ and 90 th percentile forecasts ranging between 110 and $124 \mathrm{kt}$. The forecast probability of gusts $>96 \mathrm{kt}$ was greater than $50 \%$ for five out of six sites.

The maximum sustained wind speeds generated by Irma were much less intense, and 3-h forecasts initiated at 2100 UTC generate low $(<40 \%)$ probabilities of sustained category 1 wind speeds, primarily over water near the western and eastern coasts of Florida within areas covered by hurricane warnings (Figs. 1a, $7 \mathrm{a})$. However, the probability of category 1 gusts was considerably higher along both coasts with nonzero values well inland (Fig. 7b). Corresponding paintball and 90th percentile plots show that only a few members have regions of sustained category 1 winds while the over-ocean maximum values do not exceed $75 \mathrm{kt}$.
Sustained wind speeds diminished quickly over land owing to increased surface roughness inducing greater frictional drag. For gusts greater than $64 \mathrm{kt}$, forecast probabilities are much higher, with nearly all members generating large areas and maximum gusts in excess of $80 \mathrm{kt}$ present near the eastern Florida coast. Sustained wind observations ranged from 54 to $62 \mathrm{kt}$ at six sites along the eastern coast of Florida between 2100 and 0000 UTC with gusts ranging from 74 to a maximum of $97 \mathrm{kt}$ at Deerfield Beach (Table 4, Fig. 6b). (Note that this measurement was from a $15-\mathrm{m}$ tower.) The 90th percentile forecasts initiated at 2100 UTC generated sustained wind speeds between 54 and $67 \mathrm{kt}$ and gusts ranging between 71 and $82 \mathrm{kt}$ at all sites, which are consistent with observations. Finally, the forecast probability of sustained category 1 wind speeds was less than $30 \%$ for all sites and less then $10 \%$ for five out of six sites. Hence, the WoF system generally did not forecast hurricane conditions over this region during this period. No gusts greater than $96 \mathrm{kt}$ were observed or forecast for Irma during this period.

MULTI-THREAT FORECASTS. In addition to providing probabilistic guidance on tornado and straight-line wind threats, the WoF system has been

TABLE 4. As in Table 3, but for hurricane Irma between 2100 and 0000 UTC 10 Sep. Additional site types include RAWS = Remote Automated Weather Station and ICAO = International Civil Aviation Organization.

\begin{tabular}{|c|c|c|c|c|c|}
\hline Name & Lon $\left({ }^{\circ} \mathrm{E}\right)$ & Lat $\left({ }^{\circ} \mathbf{N}\right)$ & Time (UTC) & Site & Measurement \\
\hline Lake Worth Pier & -80.03 & 26.61 & 2100 & C-MAN & $2 \mathrm{~min} ; 10 \mathrm{~m}$ \\
\hline West Palm Beach Int. & -80.09 & 26.68 & 2101 & ICAO & $2 \mathrm{~min} ; 10 \mathrm{~m}$ \\
\hline Deerfield Beach & -80.12 & 26.29 & 2200 & RAWS & I min; 15 m \\
\hline St. Lucie Power Plant & -80.24 & 27.35 & 2304 & Weatherflow & $1 \mathrm{~min} ; 10 \mathrm{~m}$ \\
\hline Fort Pierce & -80.36 & 27.49 & 2306 & ICAO & $2 \mathrm{~min} ; 10 \mathrm{~m}$ \\
\hline Juno Beach Pier & -80.06 & 26.89 & 2354 & Weatherflow & $1 \mathrm{~min} ; 10 \mathrm{~m}$ \\
\hline
\end{tabular}

\begin{tabular}{|l|c|c|c|c|c|c|}
\hline Name & Obs: Sustained & 90th \% & Obs: Gust & 90th \% & Prob > 64 kt & Prob > 96 kt \\
\hline Lake Worth Pier & 55 & 66.7 & 79 & 82 & 0.28 & 0 \\
\hline West Palm Beach Int. & 57 & 54.1 & 79 & 75.3 & 0 & 0 \\
\hline Deerfield Beach & 61 & 58 & 97 & 75.9 & 0.03 & 0 \\
\hline St. Lucie Power Plant & 62 & 66.6 & 87 & 81.4 & 0.25 & 0 \\
\hline Fort Pierce & 62 & 58.5 & 77 & 77 & 0.02 & 0 \\
\hline Juno Beach Pier & 61 & 62.1 & 74 & 78.31 & 0.1 & 0 \\
\hline
\end{tabular}


shown to produce accurate predictions of flash flooding in Hurricane Harvey (Yussouf et al. 2018). Given the multiple threats present in landfalling TCs, the ability to provide a combined probabilistic hazard map may assist operational meteorologists in quantifying relative risks impacting specific locations and effectively communicating hazard information to the public (Demuth et al. 2012). Figure 8 shows combined probabilities of hurricane-force sustained wind speed (blues), accumulated precipitation greater than 2 in. (greens), and low-level vorticity greater than 0.0015 $\mathrm{s}^{-1}$ (reds) for 3-h forecasts initiated at 2100 and 0000

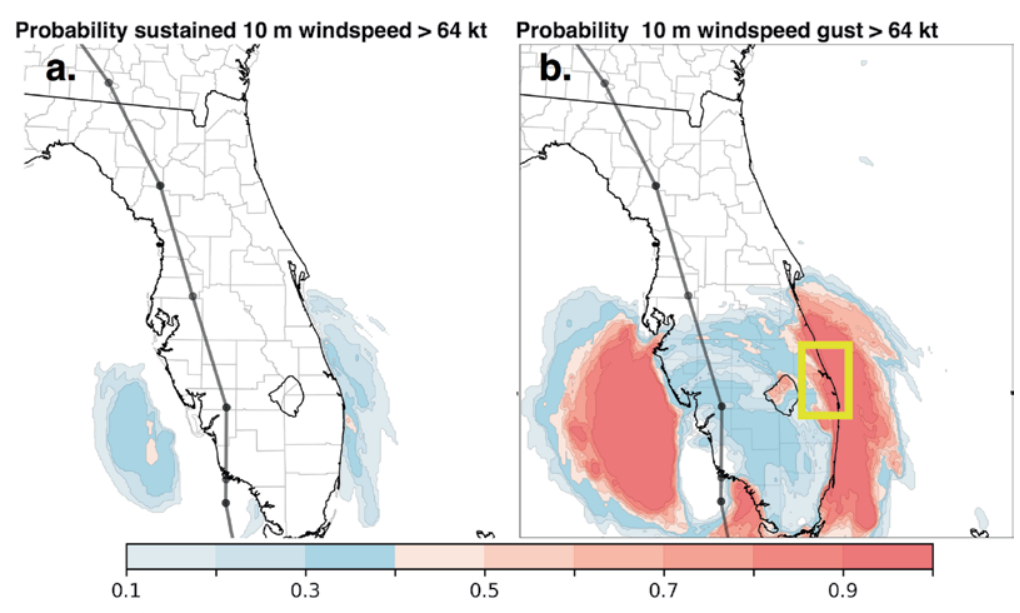

Paintball of sustained $10 \mathrm{~m}$ windspeed $>64 \mathrm{kt}$

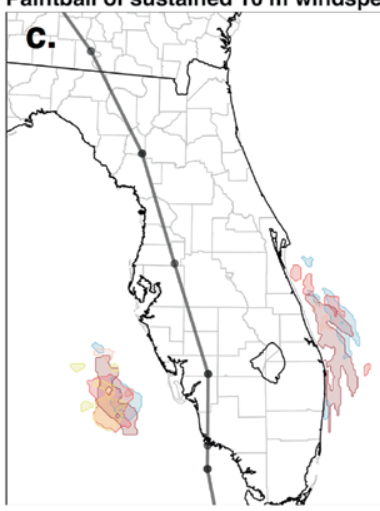

90th Percentile of sustained $10 \mathrm{~m}$ windspeed 2100 - 0000 UTC

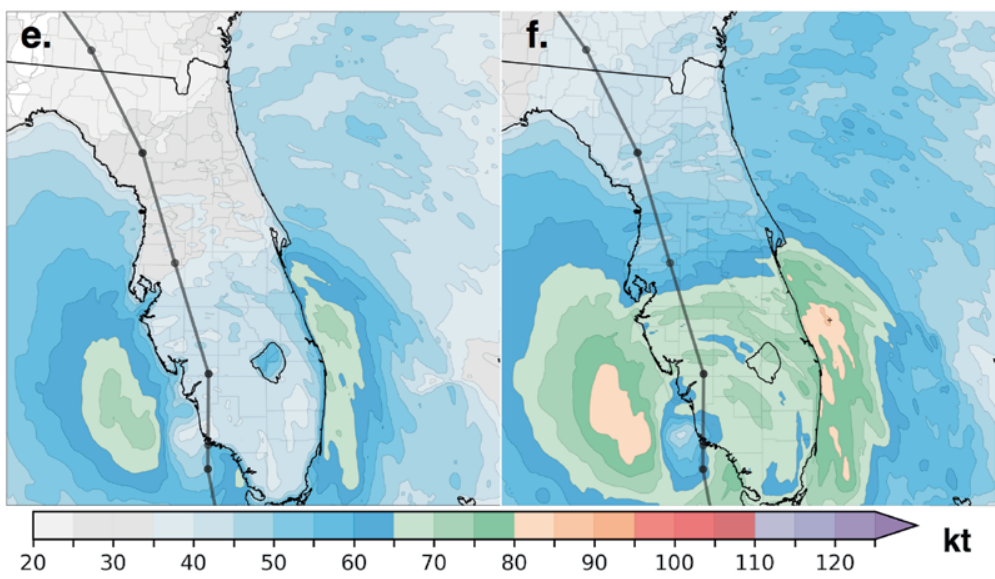

FIG. 7. As in Fig. 5, but for a 3-h forecast initiated at 2100 UTC 10 Sep. Also, the right hand panels represent gusts greater than $64 \mathrm{kt}$ and not gusts greater than $96 \mathrm{kt}$ as in Fig. 5 .
UTC for both hurricanes (Figs. 8a,b). In both forecast periods, Harvey's circular area of hurricane force winds is evident, collocated with an area of heavy precipitation generated from eyewall convection. The overall area of high winds coupled with heavy precipitation was rather small. To the north of center, a large area where storm rotation is the primary threat was present between 2100 and 0000 UTC. Beginning at 0000 UTC, the coverage of the rotation threat decreases, but remains significant in a linear band, while the flooding threat in this location also increases. Farther south, the threats of high winds and heavy precipitation associated with the eyewall have reached the coastline.

In the case of Irma, the overall wind threat was much lower and confined to small areas along the Florida coasts (Figs. 8c,d). Conversely, the threat for significant low-level rotation was much greater and covers much of the eastern Florida coast and areas farther inland. The heavy precipitation threat was also apparent and maximized on the northern side of the center of the circulation. Between 2100 and 0300 UTC, all threats remain similar in magnitude but shift northward along the track of the hurricane. It is anticipated that this multi-threat visualization tool would allow forecasters to more easily emphasize certain threats in particular areas when generating public forecast material and assess where the highest impact from all forms of severe weather may occur.

CONCLUSIONS. The WoF system products presented in this article are intended to provide examples of the capabilities of WoF in predicting 
hazards within landfalling tropical cyclones. We believe these initial results indicate that the WoF concept can be applied in these situations. Further investigation on optimizing the system configuration for tropical cyclones and understanding the relationships between modeled and observed severe weather parameters is warranted. For example, the relationship between forecast low-level rotation and the

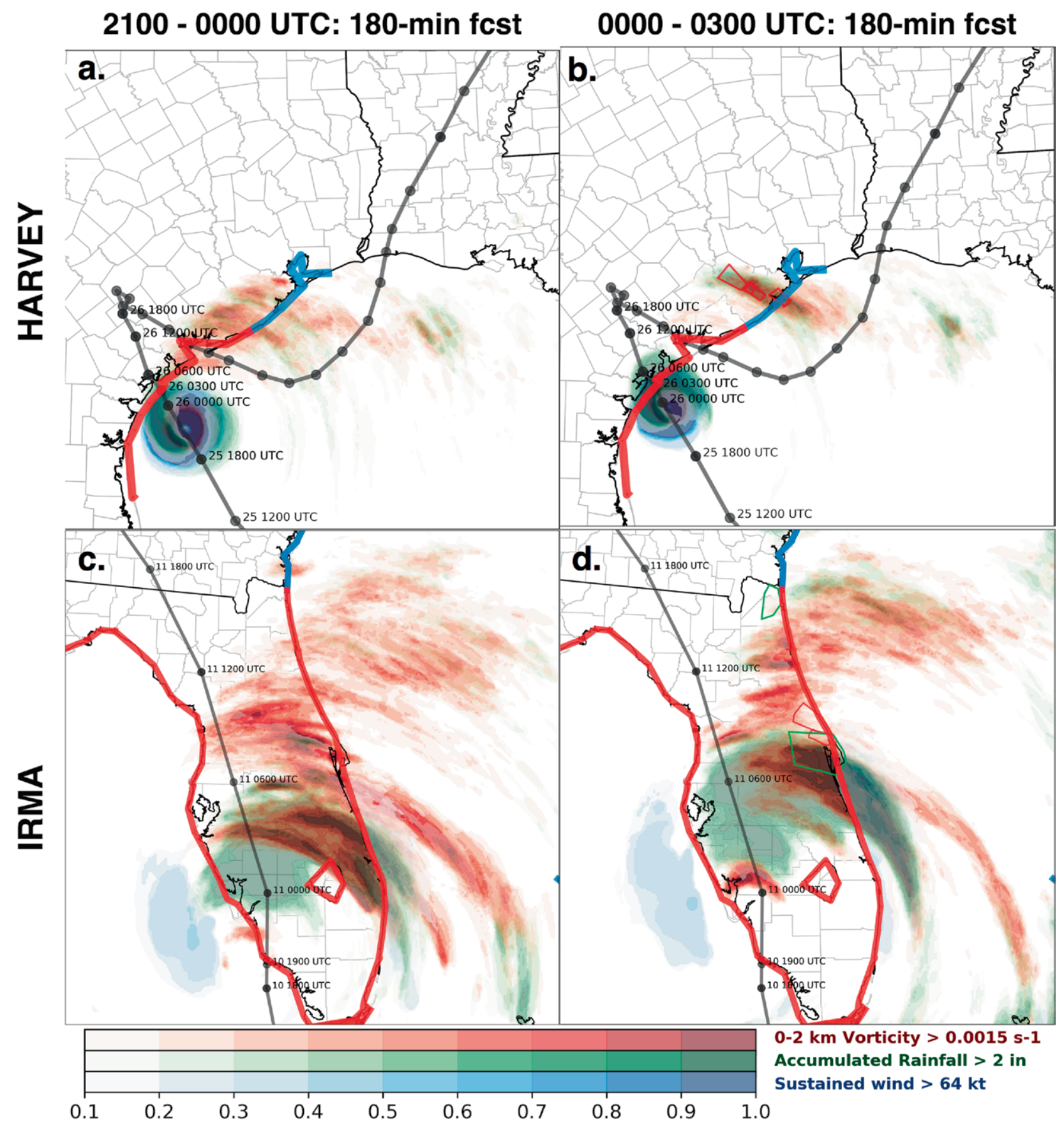

FIG. 8. Multi-threat plot showing the probability of vorticity greater than $0.0015 \mathrm{~s}^{-1}$ (reds), accumulated precipitation greater than 2 in. (greens), and sustained wind speeds greater than 64 kt (blues). Darker colors indicate higher probabilities. Three-hour forecasts initiated at 2100 and 0000 UTC for both Harvey and Irma are shown. Red (blue) lines along the coasts indicate the locations of valid hurricane (tropical storm) warnings at this time. The NHC best track location with times is also provided. Finally, red and green polygons represent tornado and flash-flood warnings valid during the forecast periods. 
occurrence of tornadoes in TC environments will require significant research going forward. Currently, it is difficult to distinguish observed and predicted rotation objects that correspond to supercell like convection from other rotation objects generated from the larger TC circulation. Understanding this relationship is vital for using the WoF system in tropical environments. In addition, the lack of observations over the oceans and the increased potential for communication failures with land-based sensors mean that any system used in coastal regions will have in increased reliance on satellite data, which brings its own challenges and uncertainties to the system. Finally, continued evolution of data assimilation and modeling systems will make building a long-term verification sample for landfalling TCs difficult.

As this article was being prepared, Hurricane Florence made landfall in North Carolina on 13 September 2018, and later Hurricane Michael made landfall in western Florida on 10 October 2018. Both hurricanes caused significant loss of life and major property damage. A version of the WoF system was run in near-real time for both hurricanes and an initial evaluation of the forecasts is underway. Forecasts for Hurricanes Harvey, Irma, Florence, and Michael are available on the project website at https://wof.nssl.noaa.gov.

ACKNOWLEDGMENTS. Funding for this research was provided by the NOAA/Office of Oceanic and Atmospheric Research under NOAA-University of Oklahoma Cooperative Agreement NA11OAR4320072, under the U.S. Department of Commerce. HRRRE initial and boundary conditions for this work were provided by the Earth System Research Laboratory, Global Systems Division. The SATCORPS satellite data used in the Warn-on-Forecast system was kindly provided by NASA Langley Research Center.

\section{FOR FURTHER READING}

Alexander, C. R., and Coauthors, 2018: Development of the High-Resolution Rapid Refresh Ensemble (HRRRE). 22nd Conf. on Integrated Observing and Assimilation Systems for the Atmosphere, Oceans, and Land Surface, Austin, TX, Amer. Meteor. Soc., 11.3, https://ams.confex.com/ams/98Annual/web program/Paper335526.html.

Benjamin, S. G., and Coauthors, 2016: A North American hourly assimilation and model forecast cycle:
The Rapid Refresh. Mon. Wea. Rev., 144, 1669-1694, https://doi.org/10.1175/MWR-D-15-0242.1.

Blake, E. S., and D. A. Zelinsky, 2018: National Hurricane Center tropical cyclone report: Hurricane Harvey (AL092017). NOAA/NWS, 77 pp., www.nhc .noaa.gov/data/tcr/AL092017_Harvey.pdf.

Cangialosi, J. P., A. S. Latto, and R. Berg, 2018: National Hurricane Center tropical cyclone report: Hurricane Irma (AL112017). NOAA/NWS, 111 pp., www.nhc .noaa.gov/data/tcr/AL112017_Irma.pdf.

Demuth, J. L., R. E. Morss, B. H. Morrow, and J. K. Lazo, 2012: Creation and communication of hurricane risk information. Bull. Amer. Meteor. Soc., 93, 1133-1145, https:/doi.org/10.1175/BAMS-D-11-00150.1.

Eastin, M. D., and M. C. Link, 2009: Miniature supercells in an offshore outer rainband of Hurricane Ivan (2004). Mon. Wea. Rev., 137, 2081-2104, https://doi .org/10.1175/2009MWR2753.1.

Green, B. W., F. Zhang, and P. Markowski, 2011: Multiscale processes leading to supercells in the landfalling outer rainbands of Hurricane Katrina (2005). Wea. Forecasting, 26, 828-847, https://doi.org/10.1175 /WAF-D-10-05049.1.

Jones, T. A., K. Knopfmeier, D. Wheatley, G. Creager, P. Minnis, and R. Palikonda, 2016: Storm-scale data assimilation and ensemble forecasting with the NSSL Experimental Warn-on-Forecast System. Part II: Combined radar and satellite data experiments. Wea. Forecasting, 31, 297-327, https://doi.org/10.1175 /WAF-D-15-0107.1.

Klotzbach, P. J., S. G. Bowen, R. Pielke Jr., and M. Bell, 2018: Continental United States hurricane landfall frequency and associated damage: Observations and future risks. Bull. Amer. Meteor. Soc., 99, 1359-1376, https://doi.org/10.1175/BAMS-D-17-0184.1.

Knupp, K. R., J. Walters, and M. Biggerstaff, 2006: Doppler profiler and radar observations of boundary layer variability during the landfall of Tropical Storm Gabrielle. J. Atmos. Sci., 63, 234-251, https:// doi.org/10.1175/JAS3608.1.

Lakshmanan, V., T. Smith, G. Stumpf, and K. Hondl, 2007: The Warning Decision Support System-Integrated Information. Wea. Forecasting, 22, 596-612, https://doi.org/10.1175/WAF1009.1.

Martinaitis, S., 2017: Radar observations of tornadowarned convection associated with tropical cyclones over Florida. Wea. Forecasting, 32, 165-186, https:// doi.org/10.1175/WAF-D-16-0105.1.

Skinner, P. S., L. J. Wicker, D. M. Wheatley, and K. H. Knopfmeier, 2016: Application of two spatial verification methods to ensemble forecasts of low-level 
rotation. Wea. Forecasting, 31, 713-735, https://doi .org/10.1175/WAF-D-15-0129.1.

—, and Coauthors, 2018: Object-based verification of a prototype Warn-on-Forecast system. Wea. Forecasting, 33, 1225-1250, https://doi.org/10.1175 /WAF-D-18-0020.1.

Smith, T. M., and Coauthors, 2016: Multi-Radar Multi-Sensor (MRMS) severe weather and aviation products: Initial operating capabilities. Bull. Amer. Meteor. Soc., 97, 1617-1630, https://doi.org/10.1175/BAMS-D-14-00173.1.

Stensrud, D. J., and Coauthors, 2009: Convectivescale Warn-on-Forecast system: A vision for 2020. Bull. Amer. Meteor. Soc., 90, 1487-1499, https://doi .org/10.1175/2009BAMS2795.1.

_- and Coauthors, 2013: Progress and challenges with Warn-on-Forecast. Atmos. Res., 123, 2-16, https:// doi.org/10.1016/j.atmosres.2012.04.004.

Thompson, R. L., B. T. Smith, J. S. Grams, A. R. Dean, and C. Broyles, 2012: Convective modes for significant severe thunderstorms in the contiguous United States. Part II: Supercell and QLCS tornado environments. Wea. Forecasting, 27, 1136-1153, https://doi.org/10.1175/WAF-D-11-00116.1.

Wheatley, D. M., K. H. Knopfmeier, T. A. Jones, and G. J. Creager, 2015: Storm-scale data assimilation and ensemble forecasting with the NSSL Experimental Warn-on-Forecast System. Part I: Radar data experiments. Wea. Forecasting, 30, 1795-1817, https://doi .org/10.1175/WAF-D-15-0043.1.

Yussouf, N., P. L. Heinselman, T. A. Jones, P. S. Skinner, D. C. Dowell, and X. Wang, 2018: Applications of Warn-on-Forecast for flash-flood producing extreme convective rainfall events. 29th Conf. on Weather Analysis and Forecasting, Denver, CO, Amer. Meteor. Soc., 2A.3, https://ams.confex .com/ams/29WAF25NWP/webprogram/Paper 345094.html.

\section{NEW FROM AMS BOOKS!}

\section{Climate in the Age of Empire: Weather Observers in Colonial Canada Victoria C. Slonosky}

Weather observers have been paying close attention to the climate for centuries, at points even hoping human activity would bring change. This book shows how and why the colonialera scientific community amassed a remarkable body of detailed knowledge about Canada's climate and its fluctuations. Covering work by early French and British observers, the book presents excerpts from weather diaries and other records that, more than the climate itself, reveal colonial attitudes toward it.

Victoria C. Slonosky studied climatology at McGill University and the Climatic Research Unit in the UK 


\section{AMS Publications introduces}

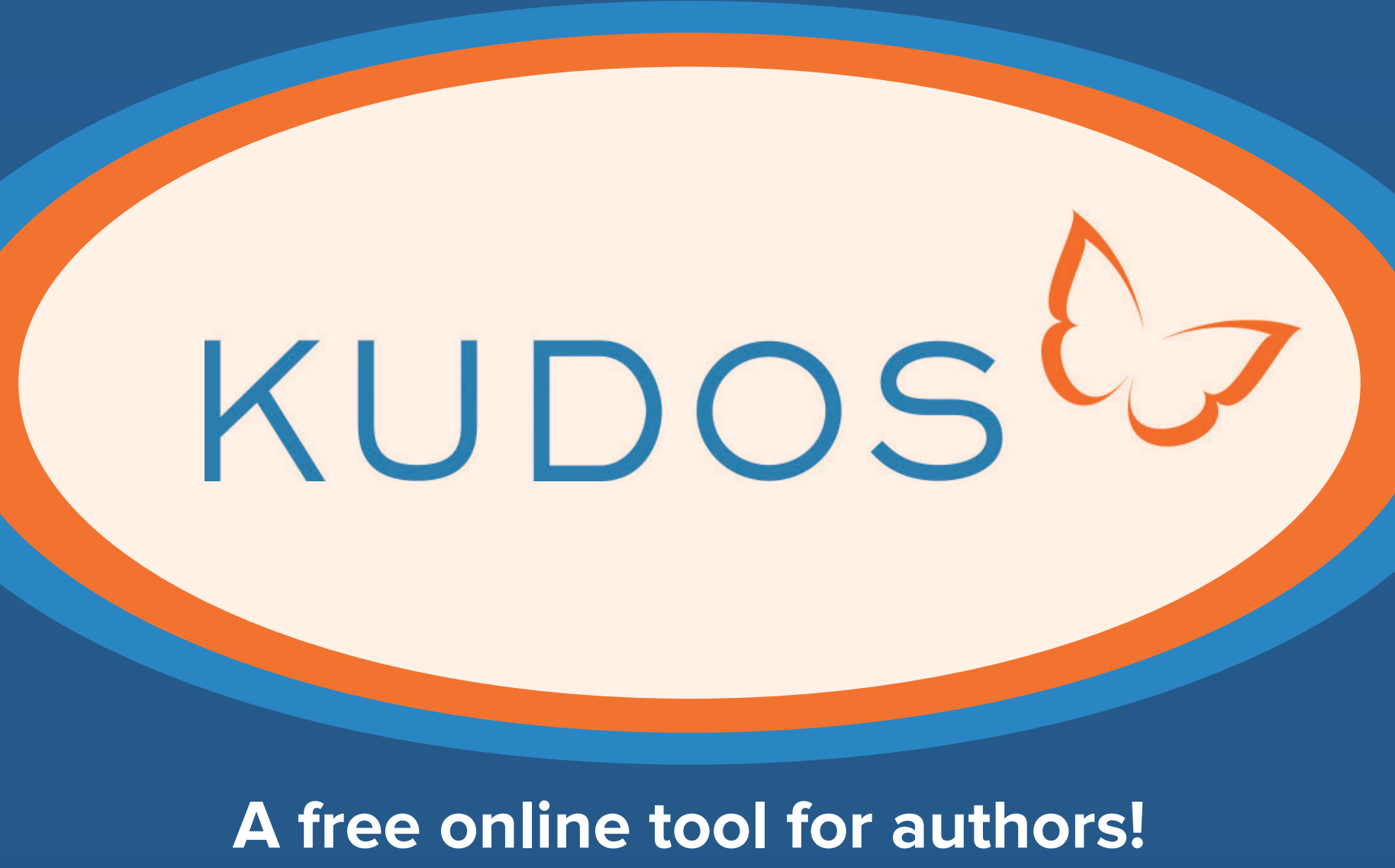

Communicate Your Research More Effectively

\section{Increase Your Work's Impact}

- Maximize citations and downloads of your article

- Open up your research to new audiences

- Explain and share your work in only 10 minutes

- Increase full-text article downloads by $23 \%$

- Access publication metrics via the author dashboard

Learn more about using Kudos with AMS

https://www.ametsoc.org/kudos/ 